\section{A first case of hemoglobin Castilla [Beta 32(B14) Leu>Arg; HBB: c.98T>G] associated with [IVS-I-1 (G>A); HBB:c.92+1G>A] mutation found in a Syrian beta- thalassemia patient}

\author{
Ahmad Shoujaa, ${ }^{1}$ Yasser Mukhalalaty, ${ }^{2}$ \\ Hossam Murad, ${ }^{3}$ Faizeh Al-Quobaili ${ }^{1}$ \\ ${ }^{1}$ Faculty of Pharmacy, Damascus \\ University; ${ }^{2}$ Thalassemia Center, \\ Ministry of Health; ${ }^{3}$ Molecular Biology \\ and Biotechnology Department, Atomic \\ Energy of Syrian Commission, \\ Damascus, Syria
}

\begin{abstract}
Beta thalassemia ( $\beta$-thal) is one of the most common worldwide inherited hemoglobinopathies. Proper identification and diagnosis of hemoglobin $(\mathrm{Hb})$ variants provide a major challenge. In this report, we describe a 1-year-old boy, presented with the diagnosis of $\beta$-TM (beta thalassemia major), has received regular blood transfusions. The molecular analysis revealed the presence of rare $\mathrm{Hb}$ Castilla [Beta 32(B14) Leu>Arg; HBB: c.98T $>$ G] variant associated with $\beta^{0}$ [IVS-I-1 $(\mathrm{G}>\mathrm{A})$; $\mathrm{AG}^{\wedge}$ GTTGGT$>$ AGATTGGT beta0] (HBB:c.92+1G>A) Mutation in beta-globin ( $\beta$-globin) gene. To our knowledge, this is the first report of $\mathrm{Hb}$ Castilla [Beta 32(B14) Leu $>$ Arg] in ExonII of $\beta$-globin gene which were found in Syrian male proband. However, we should investigate abnormal hemoglobins in patients with beta thalassemia to determine whether they have involvement with $\beta$-thalassemia mutations in the clinical case of the patients or not.
\end{abstract}

\section{Introduction}

Globally, the inherited disorder that named thalassemia is very common. It caused by having no globin chains of hemoglobin or a little of it., ${ }^{1,2}$ Beta-thalassemia ( $\beta$-thal) is one of the major types of thalassemia and it results from decrease in lack of beta-globin ( $\beta$-globin) chain production. ${ }^{3}$ Thalassemia has many clinical spectrums and the severity extend from asymptomatic thalassemia which called minor phenotype to transfusion dependent thalassemia which called major (TM) phenotype. ${ }^{4}$

Furthermore, hemoglobinopathy is a genetic disorder which is very common in the world. Suitable identification and diag- nosis of hemoglobin $(\mathrm{Hb})$ variants tool up a major challenge. ${ }^{5}$ It has been estimated that $7.0 \%$ of the population worldwide carry different types of mutations on the globin gene that alter the oxygen binding capacity of $\mathrm{Hb}$ or hamper the major structure of this molecule. The second type can be further subtyped: first, mutations impairing the globin chain synthesis of the $\mathrm{Hb}$ molecule (thalassemias) and second, those that produce structurally abnormal proteins (Hb variants). ${ }^{6}$ For the first time, the unstable hemoglobin which called Castilla [Beta 32(B14) Leu $>$ Arg; HBB: c.98T $>$ G], reported in Spain. ${ }^{7}$

We have had the opportunity to find the first observation of this abnormal hemoglobin, incidentally found in a Syrian patient suffering from a Beta-thalassemia major.

\section{Case Report}

A 1-year-old boy with the diagnosis of $\beta$-TM (beta thalassemia major) has received regular transfusions of blood since the age of 7.5 months. The parents were in a consanguineous marriage. They originated from Hama province in middle region of Syria. Institutional Ethics Committee of Damascus University in Syria approved this study.

High performance liquid chromatography (HPLC) was performed on the proband blood before the first transfusion. $2.5 \mathrm{~mL}$ of blood was collected from the members of family. We did the complete blood count (CBC) and (Sequencing) for all.

The peripheral blood was collected from the proband and her parents to isolate the genomic DNA by using the Mini kit of QIAamp DNA Blood (Qiagen, Germany) according to the manufacturer's instructions. We run the purified genomic DNA by using an agarose gel with percentage $1 \%$. By spectrophotometer from NanoVue (Germany), the quantity and quality of the DNA was determined.

By using ABI PRISM 310-DNA Analyzer from Applied Biosystem (USA), we made direct sequencing for $\mathrm{DNA}^{8,9}$ and determined the genotyping of HBB gene by using polymerase chain reaction (PCR). The suitable primers were used for three exons and tow Introns of $\beta$-globin gene including the promoter region, 5' and 3' untranslated region (UTR) sequences as previously reported. ${ }^{10}$

To verify the existence of HBD gene, two specific primer sets were designed for Ex 1 and 2 and Ex 3 including their flanking regions on the $\delta$-globin gene as previously reported. ${ }^{11}$ We used $\alpha$-Globin StripAssay from ViennaLab (Austria) to make reverse hybridization assay, this strip covers 21 of
Correspondence: Ahmad Shoujaa, Faculty of Pharmacy, Damascus University, Syria.

E-mail: ahmad.shoujaa@damascusuniversity.edu.sy

Key words: $\mathrm{Hb}$ Castilla; $\beta$-Thalassemia ( $\beta$-thal); mutations; Syria.

Acknowledgements: we thank Prof. M Kabakebi, the president of Damascus University, Prof. I. Othman, the Director General of Atomic Energy Commission of Syria (AECS) and Prof. A.H. Natoof, the dean of Faculty of Pharmacy in Damascus University for their support.

Contributions: AS wrote the study and coordinate the all work; YM collected the samples of patients; HM made the sequencing and other protocols; FA-Q, revised the study.

Conflict of interest: the authors declare no potential conflict of interest.

Received for publication: 13 July 2019.

Accepted for publication: 19 December 2019.

This work is licensed under a Creative Commons Attribution 4.0 License (by-nc 4.0).

CCopyright: the Author(s), 2020

Licensee PAGEPress, Italy

Thalassemia Reports 2020; 10:8396

doi:10.4081/thal.2020.8396

$\alpha$-thal mutations. We used specific primers and restriction enzyme to detect the $X m n-\mathrm{I}$ locus with RFLP-PCR technique. ${ }^{12}$

\section{Results}

The proband has a regular blood transfusion with interval (30-days) in average. At the age of 7.5 months, he presented with pallor and nausea. The $\mathrm{Hb}$ level was 8.1 $\mathrm{g} / \mathrm{dL}$. The mean corpuscular volume (MCV) values were 73.9. And the mean corpuscular $\mathrm{Hb}(\mathrm{MCH})$ values were $24.5 \mathrm{pg}$. He has no splenectomy yet.

Hematological and molecular data for the family were described in Table 1.

The proband's chromatogram revealed the presence of [IVS-I-1 $(\mathrm{G}>\mathrm{A})$; $\mathrm{AG}^{\wedge} \mathrm{GTTGGT}->$ AGATTGGT beta0] (HBB:c.92+1G>A) mutation and hemoglobin Castilla [Beta 32(B14) Leu>Arg; HBB: c. $98 \mathrm{~T}>\mathrm{G}]$, the proband presented with a thalassemia major.

Additionally, the proband revealed that he did not have any of common mutations of the $\delta$-thal and $\alpha$-thal. Also, the proband did not have $X m n I$ polymorphism at -158 to the ${ }^{\mathrm{G}} \gamma$-globin gene $(X m n \mathrm{I}[-/-])$. By examining the chromatogram of his parents, it was revealed that his mother carry 
Haemoglobin Castilla in the heterozygous state. This (Hb variant) was reported to the HbVar database. It has been accepted with HbVar ID as 294, and recorded with HGVS nomenclature as $H B B$ : c. $98 \mathrm{~T}>\mathrm{G}$. The chromatograms of the proband are described in Figure 1.

\section{Discussion}

This $\mathrm{Hb}$ variant was inherited maternally. The $\mathrm{Hb}$ Castilla had been barely described in the scientific literature. Describing this unstable hemoglobin $(\mathrm{Hb})$ variant reported for the first time in Spain, a case of $\mathrm{Hb}$ Castilla that was a girl patient her age is 3 years with pallor and jaundice. When she was 4 years old, the splenectomy has been done. ${ }^{7}$ The second report was a case of an 8-month-old boy with anemia, and his parents are of Northern European ancestry and have normal hematological profiles. ${ }^{13}$ In our case, the $\mathrm{Hb}$ Castilla is reported for the first time in Syria and for the third time globally. Also, the combination of $\beta^{0}$ mutation with $\mathrm{Hb}$ Castilla is reported for the first time, and it leads to $\beta$ TM phenotype.

\section{Conclusions}

We present here a case of rare variant of hemoglobin which called $\mathrm{Hb}$ Castilla [Beta 32(B14) Leu>Arg] in ExonII of $\beta$ globin gene which were found in Syrian male proband for the first time in a Syrian family. However, we should investigate abnormal hemoglobins in patients with beta thalassemia to determine whether they have involvement with $\beta$-thalassemia mutations in the clinical case of the patients or not.

Table 1. The hematological and molecular data of the family.

\begin{tabular}{|c|c|c|c|}
\hline Parameters & Father & Mother & Proband \\
\hline Sex-age (years) & M-31 & F-29 & M-1 \\
\hline $\mathrm{Hb}(\mathrm{g} / \mathrm{dL})$ & 12.6 & 9.3 & 8.1 \\
\hline $\mathrm{RBC}\left(10^{6} / \mu \mathrm{L}\right)$ & 6.98 & 5.56 & 3.30 \\
\hline MCV (fL) & 60.9 & 58.5 & 73.9 \\
\hline $\mathrm{MCH}(\mathrm{pg})$ & 18.1 & 16.7 & 24.5 \\
\hline MCHC (g/dL) & 29.7 & 28.6 & 33.2 \\
\hline $\mathrm{Hb} \mathrm{A}(\%)$ & 92.9 & 93.1 & 43.1 \\
\hline $\mathrm{Hb} \mathrm{A}_{2}(\%)$ & 5.6 & 6 & 2.4 \\
\hline $\mathrm{Hb} F(\%)$ & 1.5 & 0.9 & 54.5 \\
\hline$\alpha$ Genotype & $\alpha \alpha / \alpha \alpha$ & $\alpha \alpha / \alpha \alpha$ & $\alpha \alpha / \alpha \alpha$ \\
\hline$\beta$ Genotype & $\beta^{\mathrm{A} /} / \beta^{\operatorname{INS}-\mathrm{II}(\mathrm{G}>\mathrm{A})}$ & $\beta^{\mathrm{A} /} \beta^{\mathrm{Hb} \text { Castilla }}$ & $\beta^{\text {IVS-I-1 }(\mathrm{G}>\mathrm{A}) / \beta^{\text {Hb Castilla }}}$ \\
\hline
\end{tabular}

$\mathrm{Hb}$, hemoglobin; RBC, red blood cell count; MCV, mean corpuscular volume; MCH, mean corpuscular Hb; MCHC, mean corpuscular hemoglobin concentration.

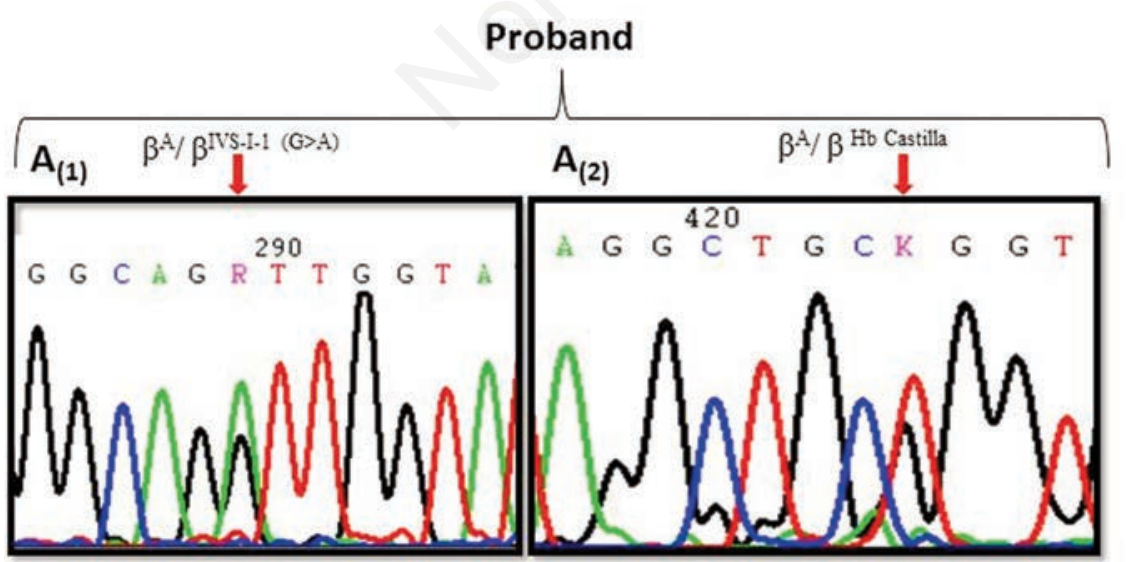

Figure 1. Direct sequencing analysis revealed the polymerase chain reaction fragment on the $\beta$-globin gene. $\left(A_{1}\right)$ the arrow indicates the substitution $(G>A)$ at Intron $I$ in the $\beta$-globin gene for the proband; $\left(A_{2}\right)$ the arrow indicates the $\mathrm{Hb}$ Castilla substitution $(\mathrm{T}>\mathrm{G})$ at Exon $\mathrm{II}$ in the $\beta$-globin gene for the proband.

\section{References}

1. Weatherall DJ, Clegg JB. Thalassemia-a global public health problem. Nat Med 1996;2:847-9.

2. Galanello R, Origa R. Beta-thalassemia. Orphanet J Rare Dis 2010;5:1-15.

3. Zhang J, Yan J, Zeng F. Recent Progress on genetic diagnosis and therapy for $\beta$ thalassemia in China and around the world. Hum Gene Ther 2018;29:197203.

4. Asadov C, Alimirzoeva Z, Mammadova $\mathrm{T}$, et al. $\beta$-Thalassemia intermedia: a comprehensive overview and novel approaches. Int J Hematol 2018;108:521.

5. Sharma S, Sharma G, Chandra J, Colah R. Hemoglobin Agenogi - A rare abnormal $\beta$ globin chain variant. Indian $\mathrm{J}$ Pathol Microbiol 2016;59:99-101.

6. Kohne E. Hemoglobinopathies: clinical manifestations, diagnosis, and treatment. Dtsch Arztebl Int 2011;108:53240.

7. Garel MC, Blouquit $\mathrm{Y}$, Rosa J, et al. Hemoglobin Castilla b32 (B14) Leu $>$ Arg: a new unstable variant producing severe hemolytic disease. FEBS Lett 1975;58:145-8.

8. Murad H, Moassas F, Jarjour R, et al. Prenatal molecular diagnosis of betathalassemia and sickle cell anemia in the Syrian population. Hemoglobin 2014;38:390-3.

9. Murad H, Moasses F, Dabboul A, et al. Geographical distribution of beta-globin gene mutations in Syria. Hematology 2018;23:697-704.

10. Sirdah MM, Sievertsen J, Al-Yazji MS, et al. The spectrum of $\beta$-thalassemia mutations in Gaza Strip, Palestine. Blood Cells Mol Dis 2013;50:247-51.

11. Liu N, Xie XM, Zhou JY, et al. Analysis of delta-globin gene mutations in the Chinese population. Hemoglobin 2013; 37:85-93.

12. Rujito L, Basalamah M, Siswandari W, et al. Modifying effect of XmnI, BCL11A, and HBS1L-MYB on clinical appearances: a study on beta-thalassemia and hemoglobin E/beta-thalassemia patients in Indonesia. Hematol Oncol Stem Cell Ther 2016;9:55-63.

13. Walker L, McFarlane A, Patterson M, et al. Hb Castilla [b32(B14)Leu $>$ Arg] Caused by a De Novo Mutation. Hemoglobin 2003;27:253-6. 